\title{
La estética de lo sencillo, el modernismo interior en La Corte de los Poetas
}

\section{Emilio José Ocampos Palomar Universidad de Sevilla}

Resumen: En este trabajo estudiaremos cómo se refleja el cambio hacia una nueva poesía modernista en La Corte de los Poetas. Nos acercaremos al modernismo interior y analizaremos tanto a los integrantes de la antología que se suscriben a esta nueva estética como a los que se mantienen en la renovación anterior. De la misma manera, nos detendremos en los poetas que abrazaron la nueva estética, pero que no fueron incluidos en la antología. Así podremos saber qué significó La Corte de los Poetas para la estética de lo sencillo.

Palabras clave: La Corte de los Poetas, simbolismo, modernismo interior, renovación estética.

\section{The Aesthetics of Simplicity, the Interior Modernism in} La Corte de los Poetas

Abstract: This work will study how change in modernist aesthetics is reflected in La Corte de los Poetas. We will approach to the predominant interior modernism of the time, and we will analyze not only the participants of the anthology, who subscribe to this new aesthetics, but also those who remain in the previous renovation. Similarly, we will stop in the poets who welcomed the new aesthetics, but who were not included in the anthology. Thus we will know what $L a$ Corte de los Poetas meant for the aesthetics of simplicity.

Keywords: La Corte de los Poetas, symbolism, interior modernism, aesthetics renovation. 


\section{INTRODUCCIÓN}

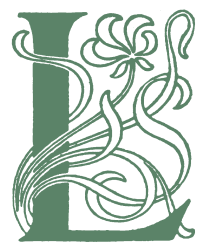

a Corte de los Poetas. Florilegio de Rimas Modernas es la antología poética del modernismo hispánico. Emilio Carrere es el encargado, por medio del librero y editor Gregorio Pueyo, de seleccionar a sesenta y siete autores. Dicha recopilación no se construye en torno a un orden cronológico o temático, sino que aparecen tanto autores vivos como muertos, españoles e hispanoamericanos, autores consagrados y otros muy lejanos al canon. De carácter ecléctico, se publica en 1906, un año después del final que, según Federico de Onís en su Antología de la poesía española e hispanoamericana (18821932), supone el periodo del «triunfo del modernismo», entre 1896 (publicación de Prosas profanas) y 1905 (publicación de Cantos de vida y esperanza). A continuación Onís aprecia una nueva orientación estética a la que da nombre y fecha: «Postmodernismo: 1905-1914», y dentro de este apartado incluye los siguientes: por un lado, el «Modernismo refrenado (Reacción hacia la sencillez lírica)»y, por otro, los «Poetas de la naturaleza y la vida campesina». El triunfo modernista fue sobre todo parnasiano, pero en torno a 1905 se va viendo desplazado por una transformación estética orientada al simbolismo. La profesora Marta Palenque, en su estudio introductorio a La Corte de los Poetas, recoge esta idea: «El silencio, la tarde, el crepúsculo, son los motivos de ahora; la influencia de Samain, Rodenbach, James ha sustituido a la de los parnasianos y decadentes; el mundo interior, la poesía de lo sencillo, se prefiere a los exotismos ya pasados de moda» (2009: XXXIV). Richard A. Cardwell, unos años antes, también aclara esta nueva estética:

Se trata de un simbolismo más puro, estética de matices, de efectos musicales, de ausencias, de elementos diferidos, de la búsqueda de la palabra adecuada, del paisaje del alma, del espejo autocontemplativo... la herencia de Bécquer y la inspiración de Verlaine, Samain, Rodenbach, Regnier, etc. (2002: 30)

Parnaso y simbolismo se entremezclaron desde los inicios del modernismo español, pero será ahora cuando los efectos, matices y rasgos simbolistas tomen independencia y adquieran predominio. Así surgirá una poesía intimista y sencilla, un modernismo predominantemente interior. 
El objetivo de este trabajo es comprobar si en la antología modernista $\mathrm{La}$ Corte de los Poetas se refleja dicha predilección estética o, si por el contrario, como afirma Celma Valero, prevalece en su selección el modernismo exterior: «La Corte de los Poetas, que pretende recoger el clima poético del momento, vuelve a incidir en los aspectos más externos de la "escuela modernista" » (2002: 94).

\section{LA ESTÉTICA DE LO SENCILLO EN LOS POETAS DE LA CORTE}

Que la fecha 1905 sea clave para el triunfo del modernismo se debe en buena parte a la publicación de Cantos de vida y esperanza. Según Federico de Onís:

En esta obra Rubén Darío renuncia al parecer a la riqueza de expresión desplegada tan brillantemente en su obra anterior y se nos muestra como un poeta más profundo y sencillo. En rigor su técnica es más difícil y más compleja en esta segunda obra; porque ha llegado en ella a la difícil sencillez de la madurez. Su lirismo es más puro y más íntimo, tanto cuando analiza mejor que lo ha hecho nadie su propia poesía, desnudando su alma ante el lector [...]. (2012: 147)

La desnudez también cala en Juan Ramón Jiménez ${ }^{1}$ y en 1904 abandona su modernismo «de no sé qué ropajes» y publica Jardines lejanos y Arias tristes siguiendo la senda becqueriana. Carrere advierte en la nota preliminar a $L a$ Corte de los Poetas su modernismo interior: «Juan R. Jiménez es un lírico exquisito. Sus últimos tres libros le han hecho una firme reputación. Delicado, íntimo, dulcemente doloroso, sus versos tienen un amable perfume de melancolía. Es personalísimo y el poeta joven más sincero» (2009: 7).

Otra obra clave y cercana a nuestra fecha es Soledades, galerías y otros poemas (1907), de Antonio Machado, donde se elude la «riqueza de expresión». Carrere respecto a la edición de 1903 dirá: «Antonio Machado, el grave sacerdote del simbolismo, es el más intenso de los poetas jóvenes. Soledades es uno de los mejores libros contemporáneos» (2009: 7).

1 Es importante señalar, en lo referente a Juan Ramón Jiménez, que todos los poemas que se recogen en La Corte pertenecen a la nueva estética. Así, aparecen poemas de Rimas, Jardines lejanos y Arias tristes. 
Tenemos, por tanto, tres autores que van a liderar un cambio hacia un modernismo interior que deje a un lado el lenguaje exótico y ebúrneo. Tras ellos estarán una serie de poetas que también respaldarán dicho cambio. Unos entenderán mejor la renovación y otros no; algunos aparecerán en La Corte de los Poetas y otros no. Esto es lo que trataremos a continuación.

La Corte se confecciona en torno a un rey llamado Darío: «Y después de Prosas profanas [...] como evocada ha surgido una brillante juventud, una lírica aristocracia compuesta por la mayor parte de los artistas que forman este florilegio» (2009: 5). Después de Prosas profanas y no de Cantos de vida y esperanza. Esto es importante porque ya se nos manifiesta que en la antología no vamos a ver la renovación que se estaba llevando a cabo. Igualmente significativo resulta que, del último libro de Darío hasta entonces, se seleccionen en La Corte los poemas en los que menos «desnuda su alma». Pero dejemos al rey y pasemos al resto de la corte, empezando por Enrique Díez-Canedo, único poeta de La Corte que aparece en la antología de Onís en el apartado «Postmodernismo: 1905-1914», concretamente en «Modernismo refrenado (Reacción hacia la sencillez lírica)». Los tres poemas que se incluyen en la antología de Carrere son posteriores a 1905. El primer poema, de Versos de las horas (1906), es «Atavismo», que encierra un verso tan significativo como «mis versos, galeones humildes y pequeños» (2009: 135). Los otros dos aún conservan tintes parnasianos. Marta Palenque sitúa esta etapa del poeta en una «variación entre un preciosismo parnasiano a lo Darío y un simbolismo de meditación y tono callado a la manera de poetas franceses como James, Laforgue o Samain» (2009: LXVII). De esta manera coincide con la siguiente cita de Onís: «En su breve obra poética hay poesías -pocas- que pertenecen al modernismo típico rubendariano y afrancesado, pero contenido y refrenado por una aspiración nueva a la perfección dentro de la sencillez y la mesura» (2012: 626).

Ramón Pérez de Ayala también aparece en la antología de Federico de Onís, pero no en el «Postmodernismo», sino en el «Triunfo del modernismo: 1896-1905». Aunque Onís es consciente de que La paz del sendero pertenece a una nueva estética:

Modernista en su obra de juventud, La paz del sendero (1903), con dejos franceses y primitivos españoles juntamente, va ascendiendo a lo largo de sus otros «senderos» simbólicos hacia una poesía muy suya, intelec- 
tual, humorística, fríamente apasionada, llena de novedades de fondo y de forma que significan la rotura de los moldes del modernismo y el avance decidido hacia una nueva poesía postmodernista(2012: 310).

La paz del sendero se presenta como su primer libro de poemas. En La Corte se añade «Almas paralíticas», donde se funde la tarde, lo humilde y la naturaleza en un espacio de paz:

A lo lejos sollozan temblando las esquilas

de las vacas, que inundan la tarde de tristeza

resignada. La paz de la naturaleza

se ha asomado a mi espíritu, y mi dolor mitiga.

Yo pienso que llamándome está la casa amiga.

$[\ldots]$

Hay mansiones modestas y de aspecto humildoso, que no han sabido nunca de alborotadas fiestas.

El corazón que tienen estas casas modestas

es apacible, es bueno, de amor y de reposo (2009: 141-148). ${ }^{2}$

Los siguientes libros de Pérez de Ayala seguirán en esta línea. Al contrario que Darío o Juan Ramón, Pérez de Ayala se presenta como poeta con esta nueva estética. Quizá, con permiso de Onís, se encuentre mejor en el «Postmodernismo» que en el «Triunfo del modernismo».

Hemos visto que Ramón Pérez de Ayala recurre al motivo de la tarde. Lo que nos lleva a hablar de la gran importancia del crepúsculo vespertino en $\mathrm{La}$ Corte de los Poetas. Las vacas de las que habla Pérez de Ayala, «que inundan la tarde de tristeza», son muy parecidas a estas otras de Juan Ramón Jiménez:

El pastor está apoyado

sobre su larga cayada,

mirando al sol de la tarde

de primavera; $y$ las vacas

van por el valle de oro

subiendo hacia la montaña,

2 Para José María Martínez Cachero, Pérez de Ayala «propone un ideal de vida campesina y sosegada, posible en un espacio físico -y acaso también simbólico- donde existe la "casa amiga" que nos alberga como podría hacerlo "un amigo fiel" » (1990: 100). 
al son lejano y dormido

de sus esquilas con lágrimas. (2009: 12-13)

La misma idea del atardecer, lo triste y lo humilde se encuentra en Antonio Machado:

La tarde está muriendo

como un hogar humilde que se apaga:

allá, sobre los montes, quedan algunas brasas...

Y ese árbol roto, en el camino blanco, hace llorar de lástima (2009: 191).

Manuel Machado hablará de «una tarde quieta / de paz [...] un silencio tan bueno que encantaba» (2009: 215) en «Vísperas». Para estos poetas, el paisaje de la tarde se corresponderá con su paisaje interior, del alma ${ }^{3}$.

Enrique de Mesa, muy cerca de Juan Ramón y Pérez de Ayala, afronta una tarde silenciosa, «de gris melancolía»:

Tornan por los senderos las ovejas

con sones melancólicos de esquilas,

que evocan dulces remembranzas viejas

de tardes eglogales y tranquilas (2009: 219).

Pero junto a este poema, en Tierra y alma (1906), tenemos otros donde desaparece el paisaje del alma y se vuelve a la tradición bucólica. A este poeta nacido en Madrid lo incluye Onís, dentro del «Postmodernismo», en el apartado «Reacción hacia la tradición clásica» y lo llama «cantor de la naturaleza y la vida campesinas, el restaurador de la tradición clásica de la poesía rústica» (2012: 689).

De José Durbán Orozco se recoge un poema de Tardes grises (1900), «El secreto»; Amelina Correa Ramón en referencia a este libro señala: «De nuevo, el tono predominante de todos los poemas, e incluso del propio título del libro, es el de la melancolía. El poeta, insatisfecho con todo lo que le rodea, se

\footnotetext{
3 Unamuno lo explica mejor: «Hay un continuo flujo y reflujo difusivo entre mi conciencia y la naturaleza que me rodea, que es mía también, mi naturaleza; a medida que se naturaliza mi espíritu saturándose de realidad externa, espiritualizo la naturaleza saturándola de la idealidad interna. Yo y el mundo nos hacemos mutuamente» (1942: 303).
} 
complace en describir su amargura, que parece impregnar de manera simbolista todos los objetos» (2001: 86) ${ }^{4}$. Sin embargo, La Corte de los Poetas se hace con «El secreto». Un poema en el que no aparece la tarde y la melancolía no está tan clara, pues el poeta lo que siente son celos: «Óyeme, a confesarlo me provoca / de los celos la horrible calentura» (2009: 248).

Marta Palenque advierte que «José Durbán se encuentra entre los almerienses atraídos por la renovación poética en pos de Rueda» (2009: LIX). Una renovación que atiende a un «ritmo natural» (Rueda, 1993; Palenque, 2008). El poeta se inspira en «la verdad gigante, la Naturaleza» (2009: 282) e interpreta su armonía. Pero Rueda queda lejos de esta estética de lo sencillo. Su modernismo no cambia ${ }^{5}$, no es interior, sino exterior, exotista y de abundantes riquezas verbales, tal y como vemos en el poema incluido en $\mathrm{La}$ Corte de los Poetas, «La risa de Grecia»:

De Chipre y de Creta, de todo el mar Jonio que siembra de risas pasando Favonio, se mira a la flota los rumbos seguir; y van en dorados brillantes tropeles, de concha y de oro sutiles bajeles y naves con proas que incrusta el zafir (2009: 279).

Rueda aparece en la antología de Onís en el apartado «Transición del romanticismo al modernismo» junto a poetas como Ricardo Gil y Francisco A. de Icaza, que también están en La Corte. Para Cardwell «La caja de música [de Ricardo Gil] y Lejanías de Icaza parecen cuajar la primera tentativa tímida de crear un simbolismo español» (2002: 39) y advierte en estos poetas:

Una serie de motivos que anuncian las estéticas del simbolismo: realidades teñidas por el ensueño o la memoria de una infancia serena [...]; el pueblo natal y «las voces amadas»; el amor por cosas y personas humildes; la auscultación del mundo interior; la evocación de momentos de ensueño; creación de un tiempo anacrónico en el cual el pasado se recrea en el pre-

\footnotetext{
4 La misma idea señalan Almudena del Olmo Iturriarte y Francisco J. Díaz Castro: «El desengaño por las ilusiones perdidas, la nostalgia por un mundo mejor e inaprensible que aboca al hastío, a una desazón muy próxima al spleen y a una melancolía que se proyecta sobre un paisaje de nebulosas crepusculares e invernales en correspondencia simbolista con las "tristes nieblas de mi alma"» (2008: 139).

5 «La autoridad de los parnasianos pierde fuelle ante el mundo interior, callado y sencillo de los versos de Albert Samain, Georges Rodenbach o Francis Jammes. Impasible ante estos vientos de cambio, la poética de la Naturaleza de Salvador Rueda permanece igual a lo largo de los años» (Palenque, 2008: 91).
} 
sente mediante el proceso creador [...]. Y todo esto como baluarte o refugio del mal metafísico y de las fuerzas destructoras del tiempo; les atormenta el sentido de pérdida y ausencia. (2002: 39)

Todos los poemas de Icaza son de Lejanías (1899). En «Preludio» encontramos la memoria de la infancia:

La azul diafanidad de la distancia en el cuadro los términos reparte, aquí mi juventud, allá mi infancia, y entre las dos, la pátina del arte... la azul diafanidad de la distancia (2009: 181).

En «Invernal» aparece el recuerdo de un pasado tranquilo junto al hogar sencillo:

Vuelva al hogar: le esperan donde hay amor y lumbre;

la llama brilla alegre, y en el rojizo fondo, de espaldas a la sombra, pensando en él se agrupan muy cerca unos de otros (2009: 187).

En «Reliquia» llama la atención la solemnidad que se le concede a lo evocado, «yo les rezo a mis recuerdos» (2009: 189), y en «Paisaje de sol» se canta el mundo interior, la correspondencia entre el poeta y el paisaje, pero a través de la imaginación ${ }^{6}$ :

Llego al lejano huerto; bajo la parra que da sombra a la escena que me imagino, resuenan los acordes de la guitarra; rompe el aire una copla que ensalza el vino... y al monótono canto de la cigarra avanzo triste y solo por el camino (2009: 184).

Finalmente, en «Himno y lira» y «Palabras sinceras » se manifiesta el legado de Bécquer ${ }^{7}$ y emociona la búsqueda de la verdadera esencia de la palabra:

\footnotetext{
6 La imaginación y la memoria, como forma de trascender la realidad material, servirán a los poetas simbolistas para hablar del paisaje del alma.

7 «En Gil e Icaza se destacan el elemento espiritual e imaginativo becqueriano» (Cardwell, 2002: 39). La poética becqueriana coincide con lo expresado en la nota anterior.
} 
Las palabras se esculpen o se esfuman;

les das la forma y a la vez la esencia (2009: 181).

En cambio ¡cuánta ternura,

qué bien sentida y qué honda:

cuatro palabras sentidas

y en un beso, el alma toda!... (2009: 186).

En cuanto a Ricardo Gil, solo hay en La Corte de los Poetas un poema de La caja de música (1898), «Duda», quedando este muy lejos de la nueva estética. Igualmente ocurre con «Humo», de De los quince a los treinta (1885). Cardwell define este poemario como una reacción ante el materialismo y el industrialismo y lo identifica con el Volksgeist y el simbolismo:

Al evocar el idilio rural, al identificarse con el espíritu del pueblo, convierte en sentimentales los aspectos humildes y patéticos, los objetos domésticos (una caja de música, un atril, un bastón, una rueca), hace lírico el dolor, lo feo; incluso la muerte [...]. Las evocaciones del campo con sus ritmos estacionales, las evocaciones de la gente humilde volviendo de sus tierras acompañada de la campana del Ángelus, o las madres durmiendo a sus niños o las abuelas sentadas a la rueca, temas que aparecen en las representaciones simbolistas de Arias tristes, Pastorales, Sonata de otoño, Camino de perfección o La ruta de don Quijote, reflejan y afirman la presencia lograda de este proceso (2002: 38).

Los comentarios de Cardwell sobre la poética de Gil e Icaza podemos aplicarlos a la obra de José de Siles. Este poeta nacido en Puente Genil pone su mirada en los seres más humildes que viven rodeados de naturaleza. Para él, ahí radica lo puro, lo que él denomina «la calma»: niños, trabajadores, pastores, animales, etc. Entiende la infancia como la edad más pura y el paso del tiempo como la causa del dolor. Además, reacciona contra el materialismo oponiendo la espiritualidad de la poesía o, mejor dicho, de su poesía, la cual irradia sencillez lírica. Los poemas de Siles que se encuentran en La Corte no son los más representativos de esta estética simbolista ${ }^{8}$. Se echa en falta

8 En la estrofa VIII de «La amada misteriosa» Siles confiesa su predilección por una poética interior, del alma, rechazando lo exterior, lo ornamental: « $\mathrm{Al}$ engarzar las rimas, como perlas / de artístico collar, pensad que ornato / exterior no más son de la hermosura / a quien debéis rendir férvido culto. / Líneas o notas, voces o matices / ¿qué son sino los relieves de la idea? / El lienzo, el mármol, el compás, la estrofa, / ¿qué son sino los moldes de lo bello? / Mas, la eterna beldad yace en el alma, / en el alma de todo. Sed los buzos / de la esencia suprema» (1905: 85). 
su memoria de la infancia y su pena por un pueblo que se ha visto obligado a abandonar, idea que empapa prácticamente toda su obra. En la antología que nos ocupa lo que vemos es un par de poemas (ambos de Los fantasmas del mundo, 1905) donde Siles se decanta por el lado de los humildes. En «Mis candidatos» leemos:

Votaré a los alados, dulces cantores, que de las sacras selvas son los tenores... Os votaré sin farsas, joh pajarillos!, porque sois tan hermosos como sencillos; porque estimáis ser libres vuestro tesoro, aunque os dieran, en cambio, prisión de oro; y porque generosos, siendo a porfía, dedicáis vuestros himnos al rey del día, a los pobres labriegos tiernas cantatas, $\mathrm{y}$ a las noches de luna mil serenatas. (2009: 60)

Y en «El Dios de los humildes»:

El que el lecho de pluma trocar suele, para el rico intranquilo, en duras zarzas;

y en la senda del pobre bellas rosas tal vez hace que nazcan.<smiles>C1[AlH][AlH]1</smiles>

Es el Dios del que sufre, del que lucha; del que lleva a sus labios hiel amarga; de aquel que entre el dolor no le maldice, y del polvo se alza.

\section{$[\ldots]$}

Mas, al mirar la guerra inextinguible con que los pueblos, entre sí, batallan, al sentir cómo al débil y al sencillo el poderoso aplasta (2009: 62-63).

Por el tema de los humildes también se decide otro poeta cordobés de $\mathrm{La}$ Corte: Marcos Rafael Blanco-Belmonte. En «Los pequeños» (La vida humilde, 
1906) hace una enumeración «de esos pobres que son ricos en su humilde pequeñez» (2009: 319): los sembradores, los pescadores, los mineros, etc. Y aparecen dos motivos que ya hemos visto antes: primero, el sonido triste de las esquilas al atardecer: "Y he sentido las esquilas que al tañer en los apriscos / entonaban dulcemente la canción crepuscular» (2009: 317); segundo, la tarde tranquila en la naturaleza: «Y he dormido sobre rosas en la huerta cervantina, / y he buscado paz y calma en la tierra salmantina, / más tranquila y amorosa que materno corazón» (2009: 217). En «iAún dicen que el pescado es caro!» (Aves sin nido, 1902) Blanco-Belmonte, de nuevo, reivindica la grandeza de los trabajadores más desfavorecidos y olvidados por la fortuna, en este caso, pescadores ${ }^{9}$ :

Cuatro tablas unidas a una peña que borda con espuma el mar rugiente; una red, una barca muy pequeña, y un chiquitín, rubio y sonriente, durmiendo en pobre cuna... compendian el amor de los amores, la dicha, el bienestar y la fortuna de humildes y sencillos pescadores (2009: 322).

Amelina Correa Ramón destaca en Blanco-Belmonte la singularidad de su poesía de reivindicación social:

Cuando se habla de los «dramas del trabajo» o de las «injusticias sociales» que Blanco Belmonte canta en sus poemas, se está apuntando hacia una de las peculiaridades de su poesía, y es, en efecto, una veta social y humanitaria presente en ella, que, sin embargo, faltó con frecuencia en el modernismo español (2001: 47).

Blanco Belmonte busca el espíritu del pueblo y lo alza. Esta espiritualidad es la que lo acerca al simbolismo, pero un simbolismo diluido cuando se deja llevar por un impulso exterior y parnasiano como en «La princesa lejana» ( $\mathrm{Al}$ sembrar los trigos, 1913).

Manuel Reina, maestro y paisano de Blanco-Belmonte, incluido en La Corte de los Poetas, conjuga igualmente ambas tendencias finiseculares, aunque su

9 La pescadora pierde a su esposo e hijo en el mar. De ahí que el pescado sea caro. 
simbolismo es moderado y llega de la mano del prerrafaelismo. La profesora Marta Palenque percibe el prerrafaelismo de Reina y dice así:

Más importantes me parecen los sonetos de Manuel Reina que componen «Héroes de Shakespeare», dedicados a «Hamlet» $\mathrm{y}$ «Ofelia»; textos de filiación parnasiana pero que, sobre todo el segundo, conectan con el simbolismo [...]. Reina es sin duda una referencia interesante en la recepción de los autores y pintores ingleses, y compuso poemas como «El rey Arturo», recreación de la leyenda medieval, y «El entierro de Ofelia» (2010: 416-417).

Sin embargo, en La Corte no se recogen poemas de Reina que nos ayuden a seguir una línea simbolista. Igualmente nos ocurre con Villaespesa, Zayas, Eduardo Marquina y Martínez Sierra ${ }^{10}$, poetas en donde el modernismo interior se manifiesta levemente y no llega, por tanto, a suponer una renovación.

Luis de Oteyza también nos lleva al paisaje del alma para, después, destruirlo a golpes parnasianos. Por suerte, tenemos en la antología «La pálida canción» (Brumas, 1905):

Yo he oído muchas veces su cadencia lenta y triste, triste y vaga...

La he oído cual si dentro de mi pecho resonara.

La balada misteriosa

es reflejo de la pena de mi alma;

es la pena de mis penas...

Un arroyo, pobre esclavo de la fuerza que le arrastra, al partir, abandonando las campiñas adoradas, cierto día sollozante la cantaba (2009: 228) ${ }^{11}$.

De Vicente Medina y José María Gabriel y Galán observamos unos poemas de gran sencillez donde se recoge la voz del campesino y sus preocupacio-

10 El simbolismo de Martínez Sierra se verá mejor en su teatro.

11 El alma de las cosas, idea característica del simbolismo. En la Clave IV de Aromas de leyenda de ValleInclán vemos: «Y el agua que en la presa platea sus cristales, / murmura una oración entre los maizales» (1991: 54). 
nes $^{12}$, pero, como bien observa Marta Palenque (2009: LVII), pertenecen más a la estética costumbrista decimonónica que a la renovación del fin de siglo. Podemos añadir que los poemas son ricos en hablas campesinas, pero pobres en la profundización de un mundo interior.

De Leopoldo Lugones se selecciona un poema de corte parnasiano («Gesta magna»). Carrere podría haber escogido poemas de Los crepúsculos del jardin (1905) donde vemos al Lugones más simbolista. Algo similar ocurre con Amado Nervo, del que no se recogen los poemas que lo relacionan con la nueva estética. Aunque no sabemos si Carrere la hubiera incluido, la renovación de Amado Nervo será más tardía y lenta. Empieza con Los jardines interiores (1905) y sigue con En voz baja (1909), Serenidad (1914) y Elevación (1917). Tal y como señala Onís:

Su obra [...] en sus mejores momentos, llena de profundo y sencillo sentido humano. Aunque cultivó algunos de los aspectos exteriores y fastuosos del modernismo, era un poeta para hablar «en voz baja», y fue siendo mejor poeta conforme se fue desnudando de los adornos y llegó a dar, en forma pobre de tan sencilla, sus emociones íntimas y sus preocupaciones trascendentales (2012: 397).

En definitiva, este análisis que hemos llevado a cabo sobre la renovación estética en La Corte nos muestra el desequilibrio de la antología a la hora de reflejar la poesía del momento. Y mucho más cuando descubrimos que hay poetas muertos como José Asunción Silva o Julián del Casal; poetas, eso sí, igual que José Martí o Manuel Gutiérrez Nájera, de anticipación simbolista, pero lejos cronológicamente de la renovación que se produce a partir de 1905.

\section{POETAS AUSENTES EN LA ANTOLOGÍA}

De Valle-Inclán la crítica ha destacado su simbolismo en la narrativa ${ }^{13}$ y en el teatro (Oliva, 2002), pero también en la poesía que es lo que aquí nos ocu-

\footnotetext{
12 Richard A. Cardwell habla de que «sus versos raramente hablaron de los problemas reales del campo» (2002: 37).

13 Sonata de Otoño es para Richard A. Cardwell (2002: 46) una de las obras con la que se plasma la estética del simbolismo en España. Para Giovanni Allegra (1986: 331-332) las Sonatas y La lámpara maravillosa son de tendencia prerrafaelita.
} 
$\mathrm{pa}^{14}$. De esto se ha encargado Miriam Sánchez Moreiras que analiza Aromas de leyenda (1907) en clave prerrafaelita y simbolista. Moreiras deja claro cómo Valle-Inclán se detiene en la infancia perdida y en la vida campesina, ideal:

El pasado lo constituyen las escenas de la vida campesina que pertenecen a la infancia del poeta; la utilización de formas verbales en presente y pretérito imperfecto (el «presente del pasado») acentúa la sensación de estatismo y la impresión de estos recuerdos, que parecen flotar en un eterno presente. El presente es el camino por el que el yo lírico vaga desde que abandonó el paraíso en la tierra y la infancia. El tiempo ambivalente del relato primero resulta, pues, de la confluencia de un pasado estático, tiempo de la felicidad (y del recuerdo de «lejanas memorias»), y un presente dinámico, tiempo del dolor (2005: 434).

Palabras que se acercan a las de Cardwell, y que ya hemos comentado, cuando hablaba de la «creación de un tiempo anacrónico en el cual el pasado se recrea en el presente mediante el proceso creador» (2002: 39). Valle- Inclán publica sus primeras poesías en 1907. Quizá el hecho de que no aparezca en La Corte se deba tan solo a una cuestión de tiempo.

En 1907 también publica Miguel de Unamuno su primer libro de poemas: Poesías. Unamuno, a veces mal entendido por la crítica, comparte con la estética simbolista el rechazo al materialismo y al industrialismo, la búsqueda espiritual mediante una poesía de música interior. Se sitúa, como afirma Celma Valero (2002), en contra de la musicalidad externa, de lo artificioso. Conocida es su animadversión hacia el modernismo parnasiano: «Todo eso de que riman los cisnes de mullido plumaje con las nieves del monte me parece de receta poética, triquiñuelas de escuela. Estoy harto de cisnes, sátiros, crisantemos, Pan, Afrodita, centauros... y toda la faramalla pseudo-clásica» (1958: 274).

Tanto Valle- Inclán como Unamuno aparecen en la antología de Onís en el «Triunfo del modernismo». Pero, como hemos visto y al igual que Pérez de Ayala, debido a su debilidad común hacia la nueva estética, nos parece mejor incluirlos en el «Postmodernismo».

14 Cf. Montero Delgado, Juan (1998), «Claves líricas de Valle-Inclán: composición y significado», en Boletín de la Biblioteca de Menéndez Pelayo, 74, págs. 207-258. 
Estos serían los dos grandes poetas ausentes, pertenecientes al modernismo interior, que posiblemente hubiesen entrado de publicar sus poemas antes, pero hay algunos más como Fernando Fortún (Reliquias ${ }^{15}$, 1914), José García Vela ${ }^{16}$ (Hogares humildes, 1909) o Andrés González Blanco ${ }^{17}$ (Poemas de provincia, 1910). A estos poetas, junto a Ramón Pérez de Ayala, José María Martínez Cachero (1990) los definirá bajo la etiqueta de «modernismo no-exotista». Por supuesto que habrá más poetas que después de 1905 se dejen influir por la renovación, como Tomás Morales o Rafael Lasso de la Vega, pero aquí hemos querido mostrar a los más significativos continuadores.

\section{CONCLUSIONES}

A pesar de que La Corte no se unifica en torno a una única estética, pues aparecen poetas y poéticas muy desiguales, hemos querido estudiar cómo se refleja en ella la renovación modernista hacia una poesía sencilla, latente ya a partir de 1905. De algunos poetas se incluyen en la antología poemas significativos de esta nueva estética; de otros, pocos o ninguno. Lo que hemos pretendido aquí ha sido marcar la línea del modernismo interior, o simbolismo, del florilegio, viendo cómo hay poetas que contribuyen de manera decisiva a esta renovación.

Pero esa línea atraviesa a pocos poetas. Si quitamos a los que alternan con el parnasianismo y a los que anuncian el simbolismo sin llegar del todo, solo nos quedan Juan Ramón Jiménez, Antonio Machado, Manuel Machado y Ramón Pérez de Ayala. Tiene razón Celma Valero (2002: 94) cuando dice que la antología fracasa, pues vuelve a caer en el modernismo exterior, el cual habían abandonado ya los grandes poetas.

Por último, hay que añadir que la ausencia en $\mathrm{La}$ Corte no es de poetas, sino más bien de poemas. Los verdaderos ausentes, por tanto, son los poemas que podrían haber llenado la antología con la nueva inclinación estética.

15 Poemario póstumo que recoge poemas publicados aproximadamente desde 1907.

16 Este poeta asturiano hace presencia en el «Postmodernismo» de la antología de Onís, dentro del «Modernismo refrenado (Reacción hacia la sencillez lírica)».

17 De Andrés González Blanco sí se publicaron poemas apegados a esta nueva estética antes de la publicación de La Corte de los Poetas. Tal y como apunta José María Martínez Cachero (1990: 102), desde 1904 se publican poemas en revistas y diarios que luego se recogerán en un libro bajo el nombre de Poemas de provincia. 


\section{REFERENCIAS BIBLIOGRÁFICAS}

Allegra, Giovanni (1986), El reino interior: premisas y semblanzas del modernismo en España, Madrid, Ediciones Encuentro.

CARDWELL, Richard (2002), «"La poesía moderna, modernísima, poesía, quizás, del futuro". Los orígenes del simbolismo en España», en Anales de literatura española. Simbolismo y modernismo, 15, págs. 27-47.

Carrere, Emilio (2009), La Corte de los Poetas. Florilegio de Rimas Modernas, ed. Marta Palenque, Sevilla, Renacimiento.

Celma Valero, María Pilar (2002), «Miguel de Unamuno, poeta simbolista», en Anales de literatura española. Simbolismo y modernismo, 15, págs. 93-108.

Correa Ramón, Amelina (2001), Poetas andaluces en la órbita del modernismo. Diccionario, Sevilla, Alfar.

Martínez Cachero, José María (1990), «Modernismo no-exotista. ¿Cotidianismo, familiarismo, humildismo?», en Albaladejo, Tomás, Blasco, Javier y de LA Fuente, Ricardo (eds.), El modernismo. Renovación de los lenguajes poéticos, Valladolid, Universidad de Valladolid, págs. 93-104.

Montero Delgado, Juan (1998), «Claves líricas de Valle-Inclán: composición y significado», en Boletín de la Biblioteca de Menéndez Pelayo, 74, págs. 207258.

Oliva, César (2002), «El simbolismo en el teatro de Valle-Inclán», en Anales de literatura española. Simbolismo y modernismo, 15, págs. 109-122.

Olmo Iturriarte, Almudena del y Díaz Castro, Francisco (2008), Antología de la poesía modernista española, Madrid, Castalia.

Onís, Federico de (2012), Antología de la poesía española e hispano-americana, ed. Alfonso García Morales, Sevilla, Renacimiento.

Palenque, Marta (2008), «Salvador Rueda en el decurso de la lírica española (con tres cartas de Rueda a Marinetti en torno al verso libre)», en MONTESA Peydró, Salvador (ed.), Salvador Rueda y su época. Autores, géneros y tendencias, Publicaciones del Congreso de Literatura Española Contemporánea, págs. 91-124. 
- (2010), «La recepción del prerrafaelismo en la "gente vieja" a través de la prensa (1880-1898)», en Giné, Marta y HiBBS, Solange (eds.), Traducción y cultura. La literatura traducida en la prensa hispánica (1868-98), Bern, Peter Lang, págs. 405-428.

RuEdA, Salvador (1993), El Ritmo, ed. Marta Palenque, Exeter, University of Exeter Press.

SÁnchez Moreiras, Miriam (2005), «Prerrafaelismo y quietismo estético en Aromas de leyenda», en Cuadernos de estudios gallegos, 118, págs. 429-445.

Siles y Varela, José de (1905), Los fantasmas del mundo. Poesías, $2^{\mathrm{a}}$ ed., Madrid, Imprenta de Felipe Marqués.

UnAmuno, Miguel de (1942), Ensayos, I, Madrid, Aguilar.

- (1958), Ensayos II, Madrid, Aguilar.

Urrutia Gómez, Jorge (1980), Antonio Machado y Juan Ramón Jiménez: la superación del modernismo, Madrid, Cincel.

- (2004), Las luces del crepúsculo: el origen simbolista de la poesía española moderna, Madrid, Biblioteca Nueva.

Valle-Inclán, Ramón del (1991), Claves líricas, Barcelona, Círculo de Lectores. 
